\title{
Risk Management Processes and Analysis in Projects Construction Industry
}

\author{
Boateng Leslie Appiah \\ Faculty of School of Urban Construction and Civil Engineering, Yangtze University, Jingzhou, China
}

Email address:

kwadwoleslie@yahoo.com

\section{To cite this article:}

Boateng Leslie Appiah. Risk Management Processes and Analysis in Projects Construction Industry. Journal of Civil, Construction and Environmental Engineering. Vol. 5, No. 4, 2020, pp. 92-101. doi: 10.11648/j.jccee.20200504.14

Received: June 25, 2020; Accepted: July 10, 2020; Published: August 25, 2020

\begin{abstract}
In the area of project construction industry, risk management has become an indispensable index of concern which needs to be focused on in order to ensure effective and successful execution of projects in the construction industry. This paper focuses on risk management within projects construction field and also to find out the opinions and ideas on the significance of the construction projects risks, and also to explore the risk analysis, risk response techniques and strategies as well as risk management processes and practices in construction industry. The questionnaire prepared for the survey was distributed both via e-mail and by sending questionnaire link onto a WhatsApp platform group of the respondents and 85 member respondents results were analyzed in the form of bar charts, column chart and radar chart. The survey results revealed that majority of the total respondents are in the capacity or position as Project Managers and also have over 15 years working experience, and as well attained Master's degree qualification. It was also revealed that risk events are usually responsible for the poor delivery and quality of work, accompanied with delays and other associated losses in project construction and also risks that are associated with high probability and high impact are required to undergo further analysis, including quantification and thorough risk management. The most frequently used risk response technique according to the respondents is through the issuance of performance bonds, warranties and guarantees and also the most frequently used risk analysis practice is the Project Documented knowledge and Review Analysis. Risk management in project construction is therefore a constant learning process to constantly improve upon practices in order to adapt and increase the process efficiency of dealing with risk in construction projects as well as its successful execution.
\end{abstract}

Keywords: Risk Management, Projects Construction, Risk Events, Survey Results, Risk Response Technique

\section{Introduction}

\subsection{Risk Management}

Risk Management has been one of the major concerns of Executives and Professionals involved in executing Projects. It is also recognized as one of the greatest needs in Project Management. Systemic project risk management has an effect on a project's success, It has been found that there is a strong relationship between the amount of risk management efforts undertaken in a project and the level of the project's success [1]. Risk Analysis and Management is a key project management practice to ensure that the least number of surprises occur while your project is underway. Risk management is a technique that should be applied within the construction industry to achieve the goal of construction industry [2]. The objectives of project risk management are to increase the likelihood and impact of positive events, and decrease the likelihood and impact of negative events in the project [3]. There is the understanding that risk management will not remove all risks from the projects, but is of the purpose to ensure that risks are managed most effectively [4]. This therefore improves the chance of successful project completion and reduces the consequences of those risks.

\subsection{Risk Management in Projects Construction}

Risk management in project construction is designed to plan, monitor and control measures needed to prevent exposure to risk. To do this it is necessary to identify the risk, assess the extent of the risk, provide measures to control the risk and manage any residual risks. Risk management in construction industry is an important part of the project 
planning and management, various risks associated with construction projects such as financial risks, environmental risks, socio-economic and construction related risks are studied and dealt with in risk management [5].

\subsection{Types of Risks in Project Construction}

Many risks may crop up in the execution of projects; these might be associated with financial, socio-political, environmental, technical, external and other construction related risk. Construction risks are classified in many ways by risk types (i.e., natures and magnitudes, etc.), the sources and/or origins, or the project phase $[6,7]$. The most common risk divisions are classified in terms of probability or occurrence frequency and the scope of impact $[8,9]$. The table below illustrates the risk types in project construction $[8,9]$.

Table 1. (Risk Types in Project Construction).

\begin{tabular}{|c|c|}
\hline Risk in terms of Frequency or Probability & $\begin{array}{l}\text { 1. Systematic Risk, Otherwise market risk independent of entity control. } \\
\text { 2. Specific risk relating to specific projects, along with all variants. }\end{array}$ \\
\hline \multirow{2}{*}{ Risk in terms of Impact scope } & 1. Fixed risk, concerning the whole economic system. \\
\hline & 2. Variable risk, otherwise non-fixed concerning a given enterprise. \\
\hline \multirow{6}{*}{ Other Risk Types } & 2. Time-related risk, risks connected with failure to implement the undertaking or individual activities. \\
\hline & 3. Technical risk, connected with failure to provide quality of the finished project. \\
\hline & 4. Market risk, risks arising from market reaction to the course and outcome of the project. \\
\hline & 5. Nature risk, risks resulting from the environment, an area which man is not able to anticipate. \\
\hline & 6. External risk, risks arising from the socio - economic environment. \\
\hline & 7. Risk related to the human factor and workplace safety, risks inherent in executive teams. \\
\hline
\end{tabular}

\section{Literature Review}

\subsection{Risk Management}

Risk management is one of the nine knowledge areas propagated by the Project Management Institute (PMI). The PMBOK $®$ Guide $5^{\text {th }}$ edition defines a project risk as "an uncertain event or condition that, if it occurs, has positive or negative effects on one or more project objectives such as scope, schedule, cost, and quality".

Project Risk Management processes therefore include [3];

1. Plan Risk Management

2. Risk Identification

3. Qualitative Risk Analysis

4. Quantitative Risk Analysis

5. Plan Risk Responses

6. Risk Control and Monitoring

\subsection{Plan Risk Management}

Risk in construction projects can be unpredictable. Managing risks in construction projects has been recognized as a very important process when it is implemented in a systematic manner throughout the lifecycle of a construction project, thus from the planning to the completion stage, this therefore leads to the achievement of the project objectives in terms of time, cost, quality, safety and environmental sustainability [10].

\subsubsection{Implicit Risk Management Plan}

In dealing with risk events and overall project risk, it requires developing plans at two different levels. The implicit risk management plan is the one that deals with overall project risk and this involves analyzing the project's structure, content, context, and scope [11]. It encompasses analyzing everything besides individual risks that can derail the project. This plan deals with the "bigger picture" of the project and its impact and not an individual issue.

\subsubsection{Explicit Risk Management Plan}

Explicit risk management plan is the one which deals with individual risk events and it involves identifying, analyzing, responding to, and controlling individual risks [11].

The illustration below in simple terms defines and distinguishes between Implicit and Explicit risk management plan [11].

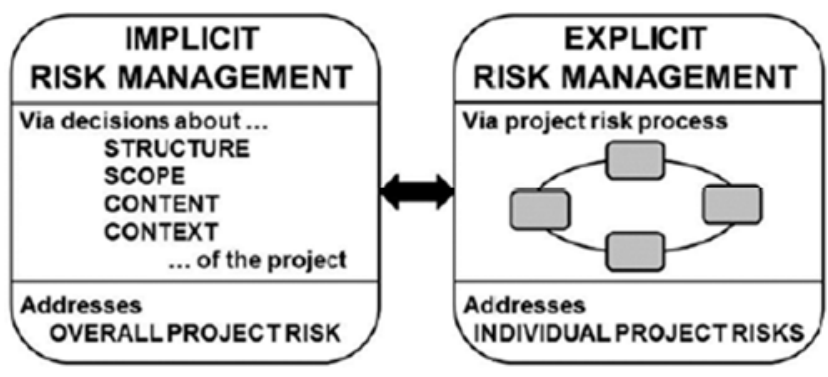

Figure 1. (Implicit and Explicit Risk Management Plan).

\subsection{Risk Identification}

Risk identification is the first and also among the most important step in the risk management process, as it attempts to identify the source, nature and type of risks as well as recognizing potential risk event occurring conditions and also able to clarify risk responsibilities in Construction project [12].

A more comprehensive approach in identifying Risk involves the use of Risk Register, Expert Analysis, Checklist Analysis and Status Report Extrapolation in assessing of potential risks as well as evaluating the likelihood that those events might happen on the project [11].

\subsection{Qualitative Risk Analysis}

This is regarded as the one that allows the key risk factors to be identified. Risk factors may be identified through a 
data-driven (quantitative) methodology or qualitative process such as interviews, brainstorming, and checklists. It is considered as an evaluation process which involves description of each risk and its impacts or the subjective labeling of risk (high/medium/low) in terms of both risk impact and probability of its occurrence [10]. The key benefit of this process is that it enables project managers to reduce the level of uncertainty and to focus on high-priority risk. Risk is a measurable part of uncertainty and is assumed as a deviation from the desired level, therefore the risk analysis is so important for project selection and coordination of construction work [13].

Qualitative analysis uses a number of tools and techniques in the assessment and classification of risk. The most important of these include [8]:

1. Risk Probability and Impact Assessment

2. Risk index assessment matrix;

3. Estimated assessment of risk significance to the project;

4. Study of project assumptions stability and project sensitivity to any changes of these assumptions;

5. Data ranking techniques in terms of usability for risk analysis;

6. Determining risk index as the resultant of probability of a particular risk factor occurrence and the significance of risk to the project in case of occurrence of a particular risk factor.

\subsection{Quantitative Risk Analysis}

A comprehensive quantitative risk analysis involves a formidable techniques and methods to investigate and analyze construction project risks. To determine risk based on quantitative analysis it is necessary to have such data as: probability of risk in a considered project that is best determined on the basis of a sufficiently large, homogeneous and reliable data sample, and valuation of risk consequences [14].

In summary, it can be unequivocally stated that both qualitative and quantitative analyses revolve around the estimation of risk and its consequences, However qualitative analysis outlines the backbone for operation, and quantitative analysis presents tangible benefits of these analyzes in figures or numeric data that form the basis for further research. Unfortunately, in practice it often happens that the tests are conducted using only one of these methods, which give an incomplete view on the matter.

\subsection{Plan Risk Response}

Plan Risk Responses is the process of developing options and actions to enhance opportunities and to reduce threats to project objectives. After classifying all risks that occur or may occur in the project, actions or strategies are needed to be undertaken to propose specific counter measures for each of the identified risk.

These actions or strategies can be divided into two folds depending upon the nature of impact of the risk on the project whether negatively or positive one. The strategies may also aim to complete neutralization of negative impacts on the project or focus on enhancing the positive impact or influence on the project [3].

\subsubsection{Strategies for Negative Risks (Threats)}

There are specific strategies which typically deal with threats or risks that may have negative impacts on project objectives if they occur, these strategies include avoidance, transference, and mitigation. The other strategy is acceptance and it can be used for both negative risks (threats) as well as positive risks (opportunities) [3]. Avoidance and mitigation strategies are usually good strategies for critical risks with high impact, while transference and acceptance are usually good strategies for threats that are less critical and with low overall impact [3]. Wang and Chou [12] reported that contractors usually use three methods to transfer risk in construction projects and these include through insurance companies, subcontracting and modification of the contract terms and conditions to client or other parties.

\subsubsection{Strategies for Positive Risks (Opportunities)}

Risk can be either positive or negative, though most people assume risks are inherently negative to the project. Where negative risk implies something unwanted that has the potential to irreparably damage a project, positive risks are opportunities that can affect the project in beneficial ways. Positive risks can also be managed to take full advantage of them.

The four response strategies to deal with risks with potentially positive impacts on project objectives are to enhance, exploit, share, and accept [3].

\subsubsection{Contingent Response Strategies or Contingency Plan}

Some responses are designed for use only if certain events occur. For some risks, it is appropriate for the project team to make a response plan that will only be executed under certain predefined condition. This kind of risk response develops an alternative method for accomplishing a project goal when a risk event has been identified that may frustrate the accomplishment of that goal. These plans are called contingency plans. Often some risks are ignored or dealt with in an arbitrary way on construction projects and it is common practice to add a $10 \%$ contingency to manage such risk [15]. However it is often the unidentified risk for which provision has not been made that may have the most significant impact on a project.

\subsection{Risk Monitoring and Control}

Control Risks is the process of implementing risk response plans, tracking identified risks, monitoring residual risks, identifying new risks, and evaluating risk process effectiveness throughout the project. The key benefit of this process is that it improves efficiency of the risk approach throughout the project life cycle to continuously optimize risk response [3].

\section{Methodology}

The general methodology of this study relies on the survey 
questionnaire which was conducted and collected from the various multi project construction Directors, project manager, site/office engineers of different sizes by mailing and also sending the questionnaire link onto their WhatsApp platform for them to respond to it.

The aims of the research is to find out opinions and ideas on the significance of the construction projects risks, and also to explore the risk analysis, risk response techniques and strategies as well as risk management processes and practices in construction industry.

\subsection{Questionnaire Structure}

The questionnaire structure of this survey was divided into three parts. The first section aims to collect the background information of the respondents, e.g. their age, position, education, work experience and professional background. The second section includes the respondents' opinion on the risk factor in terms of its probability and impact to overall construction project success. The third section includes the respondents' opinion on the risk consequences for construction project performance measures as well as the risk analysis or assessment and risk response practices.

\subsection{Questionnaire Design}

The survey questionnaire was designed and formulated by looking through the relevant literatures in the area of risk management in construction and then a pilot survey or study was conducted. The pilot survey responses formed the basis of modifying the questionnaire for the subsequent full-scale survey and therefore new inputs raised by the respondents were incorporated in in the final full scale survey questionnaire.

The questionnaire of survey was distributed either via e-mail or by sending questionnaire link onto their WhatsApp platform group. In total 89 members responded to the questionnaires and out of that 4 were incomplete so 85 respondents were used for results and analysis, which constitute $95.5 \%$ of respondents representing the overall response rate.

\section{Results Analysis and Discussion}

The survey results were analyzed using Statistical Package of Social Studies (SPSS) software. This software is one of the management tools that help in analyzing data and then comes out with a more credible and meaningful results and interpretations.

\subsection{Demographical Analysis \& Results of Survey}

Table 2. (Age of Respondent).

\begin{tabular}{llll}
\hline NUMBERS & $\begin{array}{l}\text { AGE OF } \\
\text { RESPONDENTS }\end{array}$ & $\begin{array}{l}\text { NUMBER OF } \\
\text { RESPONSE }\end{array}$ & $\begin{array}{l}\text { PERCENTAGE } \\
(\%)\end{array}$ \\
\hline 1 & 30-35 Years & 6 & 7 \\
2 & 36-40 Years & 17 & 20 \\
3 & 41-45 Years & 22 & 26 \\
4 & 46-50 Years & 28 & 33 \\
5 & Above 50 Years & 12 & 14 \\
& TOTAL & 85 & 100 \\
\hline
\end{tabular}

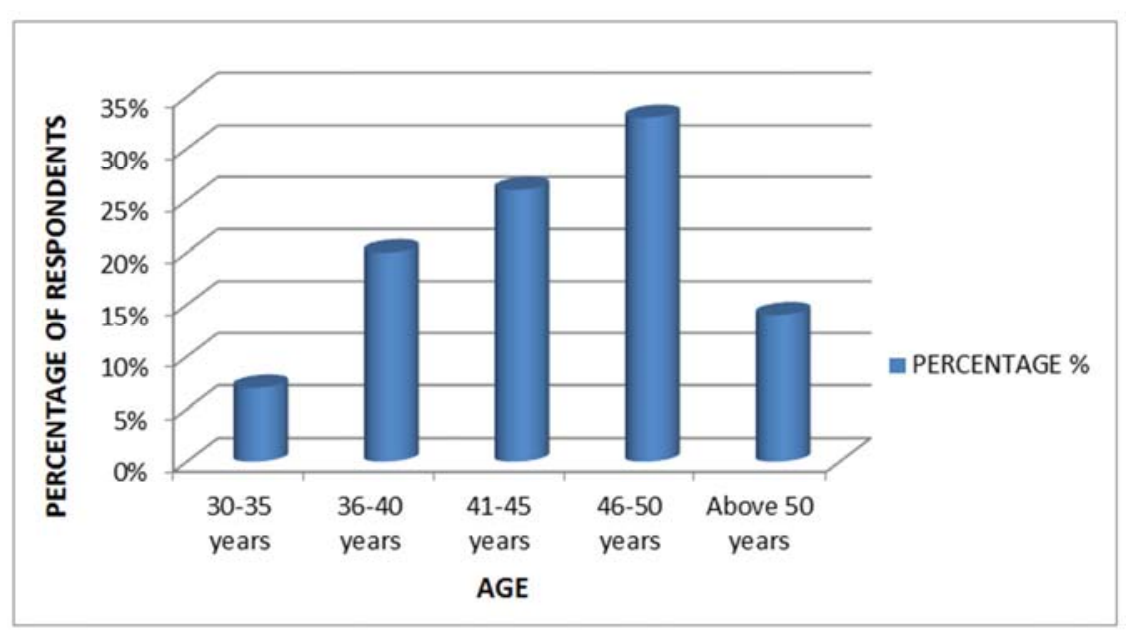

Figure 2. (Percentage age group of Respondents).

According to table 2 and figure 2 above, $7 \%$ of the respondents fall within the ages of 30-35 years, $20 \%$ of the respondents also fall within the ages of $36-40$ years, $26 \%$ of the respondents are also within the ages of $41-45$ years, $33 \%$ of the respondents fall within the ages of $46-50$ years and $14 \%$ of the respondents are over 50 years of age. It can therefore be deduced that majority of the Respondents fall within 46-50 year age group representing 33\% (one-third) of the total respondents.
Table 3. (Work Experience of the Respondent).

\begin{tabular}{llll}
\hline Numbers & Years of experience & $\begin{array}{l}\text { No. of } \\
\text { respondents }\end{array}$ & Percentage (\%) \\
\hline 1 & Less than 1 year & 3 & 4 \\
2 & From 1 to 3 years & 9 & 11 \\
3 & More than 3 to 5 years & 11 & 13 \\
4 & More than 5 to 10 years & 14 & 16 \\
5 & More than 10 to 15 year & 18 & 21 \\
6 & Over 15 Years & 30 & 35 \\
& TOTAL & 85 & 100 \\
\hline
\end{tabular}




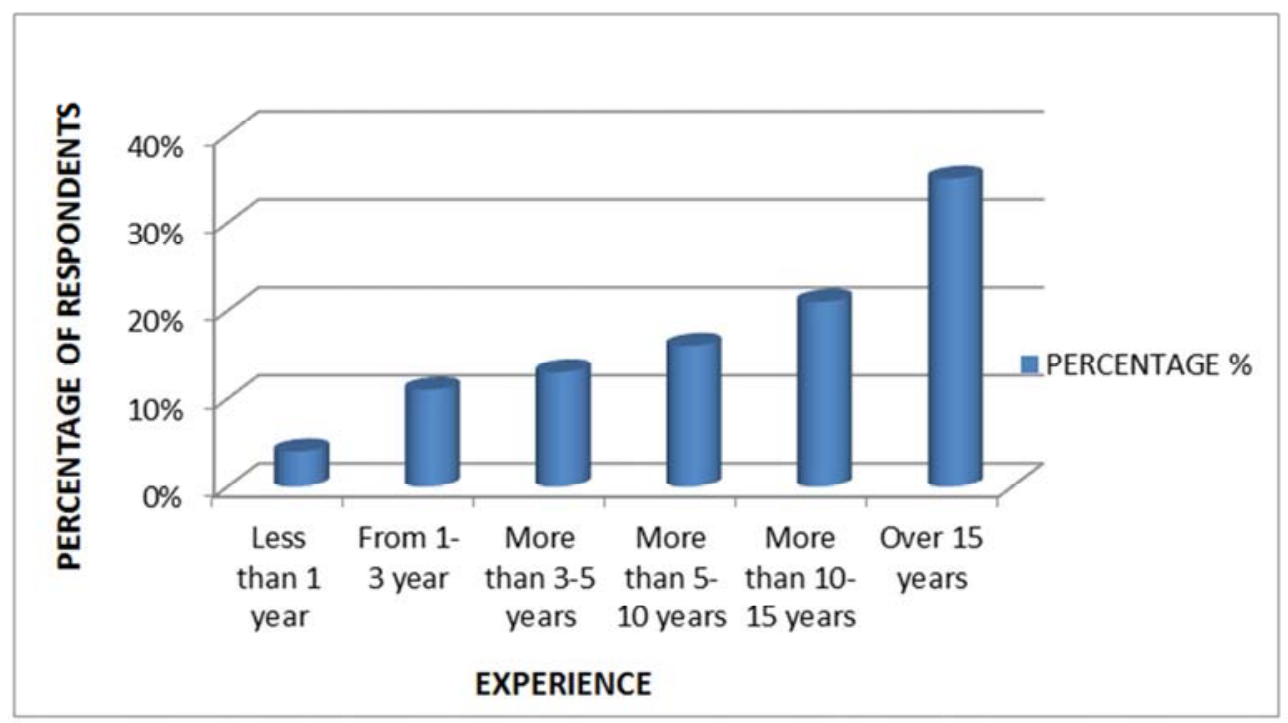

Figure 3. (Percentage years of working experience of Respondents).

According to table 3 and figure 3 above, $4 \%$ of the respondents have less than 1 year working experience, $11 \%$ also have from 1 to 3 years working experience, $13 \%$ also have more than 3 to 5 years working experience, $16 \%$ also have more than 5 to 10 years working experience, $21 \%$ also have more than 10 to 15 years working experience and $35 \%$ of the total respondents also have over 15 years working experience. It can therefore be deduced that majority of the respondents have over 15 years of experience in construction project management, representing $35 \%$ of the total respondents. In accordance with this, it can be inferred that, majority of the respondents who took part in the survey therefore have ample knowledge in the field of risk management as well as practices involved which make the respondents reliable and credible sources of information which is required to satisfy the research goal.

Table 4. (Position of the Respondent).

\begin{tabular}{llll}
\hline Numbers & Position & $\begin{array}{l}\text { No. of } \\
\text { respondents }\end{array}$ & Percentage (\%) \\
\hline 1 & Director & 4 & 5 \\
2 & Deputy Director & 10 & 12 \\
3 & Project Manager & 32 & 38 \\
4 & Site/Office Engineer & 19 & 22 \\
5 & Civil Engineer & 8 & 9 \\
6 & Others & 12 & 14 \\
& TOTAL & 85 & 100 \\
\hline
\end{tabular}

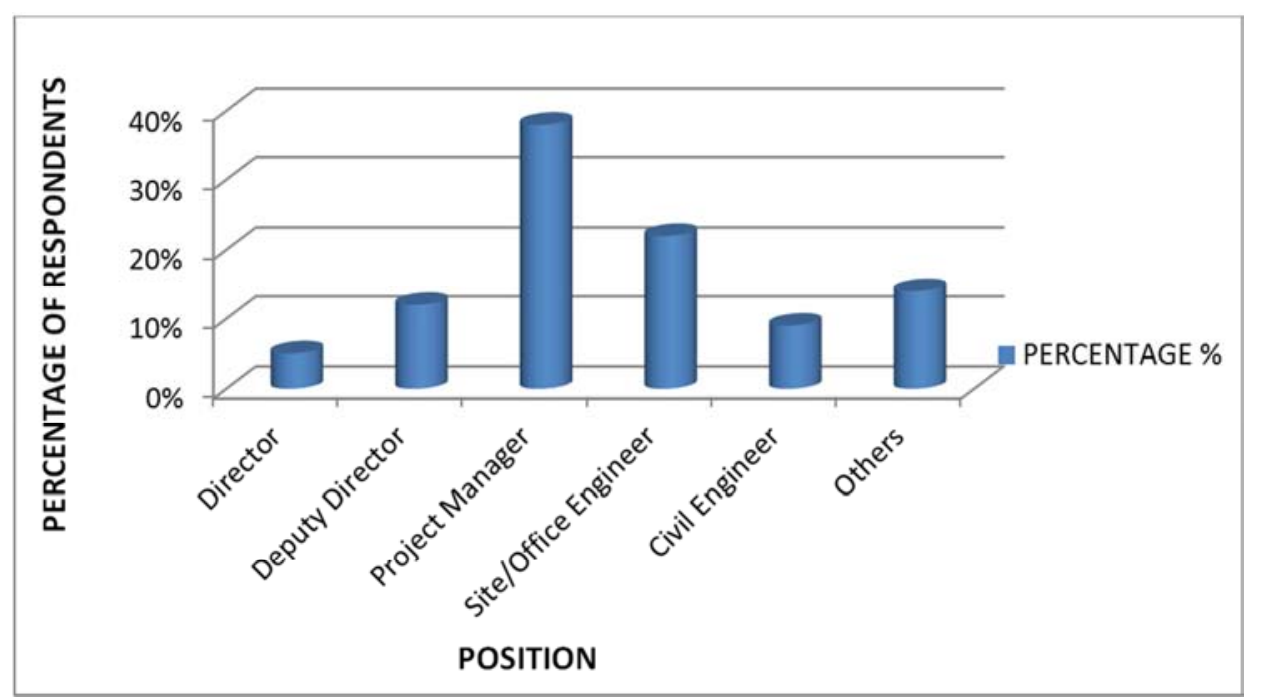

Figure 4. (Percentage Position of Respondents).

From table 4 and figure 4 above, 5\% of the respondents are Directors, $12 \%$ are Deputy Directors, 38\% are Project Managers, 22\% are Site/Office Engineers, 9\% are Civil Engineers and the rest of the respondents (Others) represent $14 \%$. It can therefore be deduced that majority of the Respondents are in the capacity or position as Project Managers representing $38 \%$ of the total respondents. 


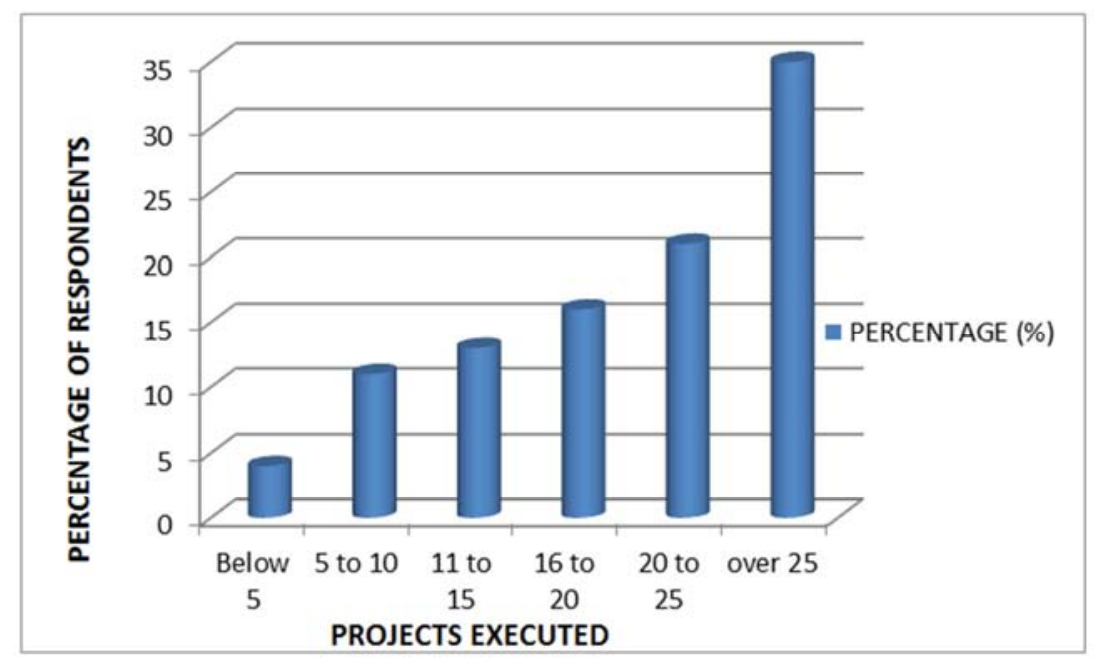

Figure 5. (Percentage Number of Projects Executed by Respondents).

Table 5. (Number of projects executed by Respondents).

\begin{tabular}{llll}
\hline Numbers & $\begin{array}{l}\text { No. of } \\
\text { projects }\end{array}$ & $\begin{array}{l}\text { No. of } \\
\text { respondents }\end{array}$ & Percentage (\%) \\
\hline 1 & Below 5 & 3 & 4 \\
2 & $5-10$ & 9 & 11 \\
3 & $11-15$ & 11 & 13 \\
4 & $16-20$ & 14 & 16 \\
5 & $21-25$ & 18 & 21 \\
6 & Over 25 & 30 & 35 \\
& TOTAL & 85 & 100 \\
\hline
\end{tabular}

From table 5 and figure 5 above, $4 \%$ of the respondents have executed less than 5 projects, $11 \%$ have executed 5 to 10 projects, $13 \%$ have also executed 11 to 15 projects, $16 \%$ have also executed 16 to 20 projects, $21 \%$ have also executed
21 to 25 projects and $35 \%$ have also executed over 25 projects. So it can be deduced that just a majority of the respondents have executed over 25 projects throughout their working experience representing $35 \%$ of the total respondents.

Table 6. (Qualification of Respondents).

\begin{tabular}{llll}
\hline \multirow{2}{*}{ NUMBERS } & \multirow{2}{*}{ QUALIFICATION } & $\begin{array}{l}\text { NO. OF } \\
\text { RESPONDENTS }\end{array}$ & $\begin{array}{l}\text { PERCENTAGE } \\
(\%)\end{array}$ \\
\hline 1 & PHD & 13 & 15 \\
2 & Master's Degree & 43 & 51 \\
3 & Bachelor Degree & 22 & 26 \\
4 & Others & 7 & 8 \\
& TOTAL & 85 & 100 \\
\hline
\end{tabular}

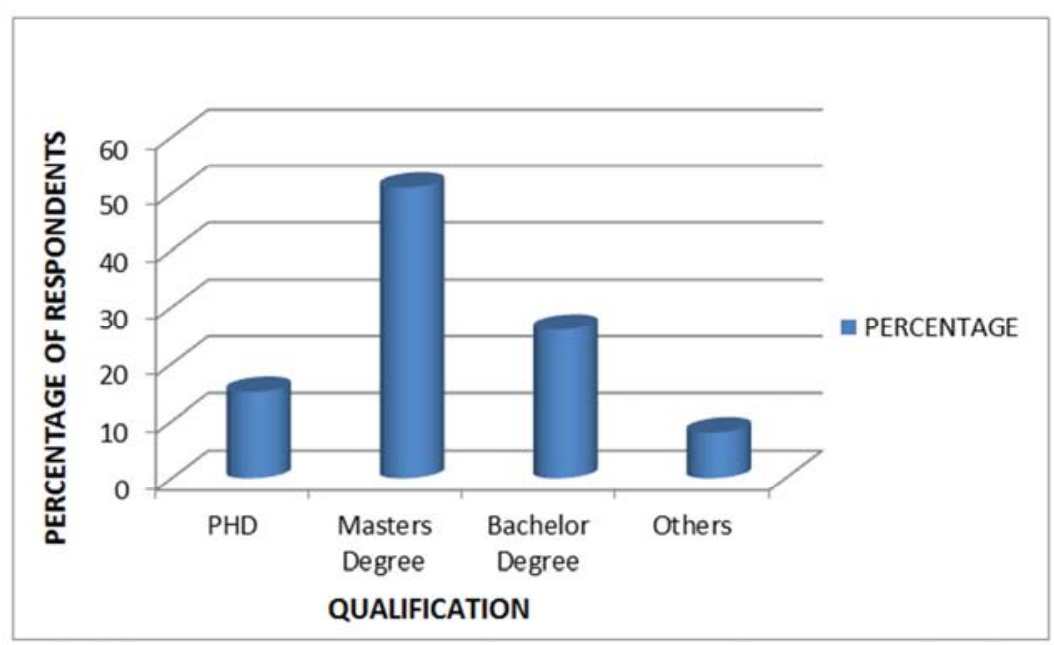

Figure 6. (Percentage Educational Qualification of Respondents).

From table 6 and figure 6 above, 15\% of the respondents have attain PHD qualification, 51\% of the respondents have Master's Degree qualification, 26\% also have Bachelor Degree qualification and the remaining $8 \%$ represent Other qualifications. It can therefore be deduced from the table and figure above that majority of the respondents have attain
Master's degree qualification which represents $51 \%$ of the total respondents. It can also be revealed that the majority of the respondents have the needed qualification and therefore have ample knowledge, skills and techniques in Risk management in construction projects. 


\subsection{Results of Risk Categories and Their Probability and Impact Assessment}

The table below shows the sources of risk in construction projects (Risk Categories) as identified by the respondents in the survey; these were further divided into eight subcategories; preliminarily Design risk, Tender risk, Detailed Design risk, Construction risk, Financial risk, Project Management risk, Environmental risk and External risk.

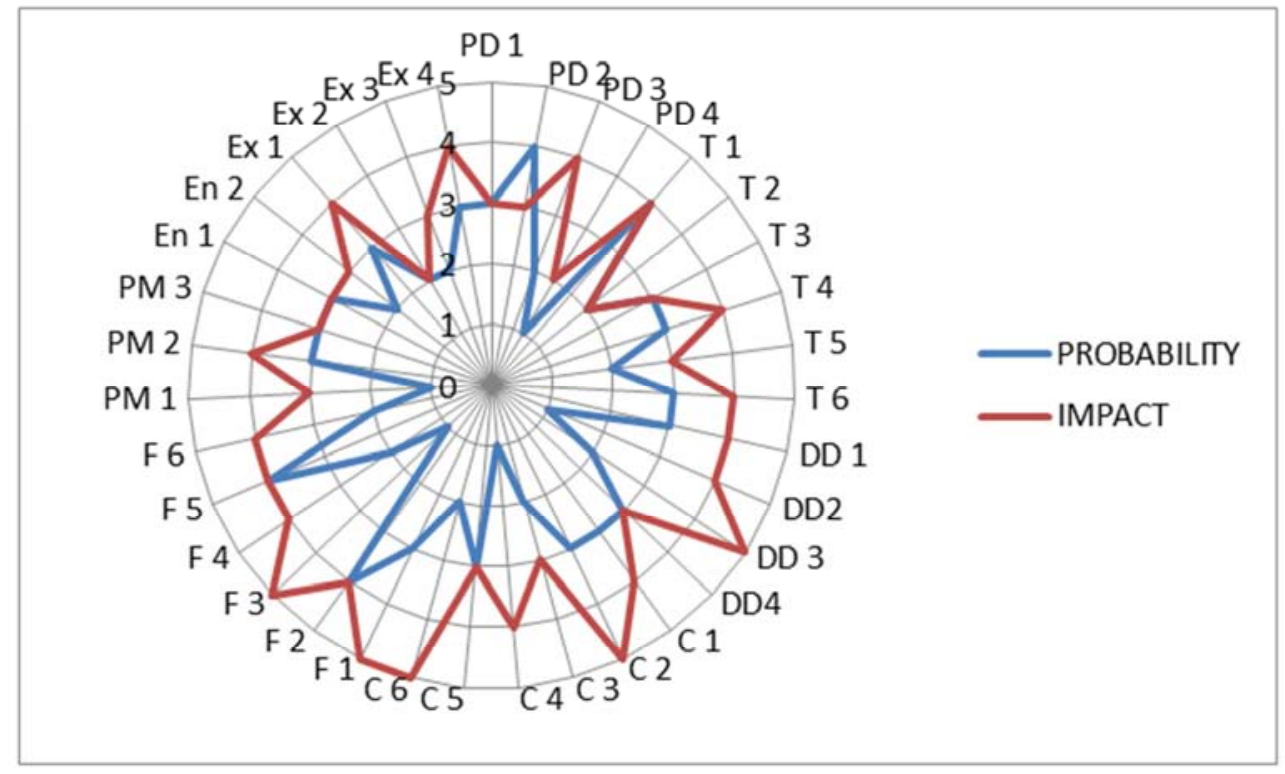

Figure 7. (Risk Categories with Probability and the magnitude of Impact identified by Respondents).

Table 7. (Risk Categories with their respective Probability and Impact identified by Respondents).

\begin{tabular}{|c|c|c|c|}
\hline CODE & CATEGORIES & $\begin{array}{l}\text { PROBABILITY } 1 \\
\text { (rare)-5 (very frequent) }\end{array}$ & $\begin{array}{l}\text { IMPACT } 1 \text { (very } \\
\text { low)-5 (very high) }\end{array}$ \\
\hline \multicolumn{4}{|c|}{ Preliminarily Design Risk } \\
\hline PD 1 & $\begin{array}{l}\text { Risk of overestimating the costs of the project (too expensive in the light of investor's } \\
\text { capabilities). }\end{array}$ & 3 & 3 \\
\hline PD 2 & Risk of poorly recognized preferences of the investors. & 4 & 3 \\
\hline PD 3 & Risk of poorly recognized competition. & 2 & 4 \\
\hline PD 4 & Risk of poor self-esteem. & 1 & 2 \\
\hline \multicolumn{4}{|c|}{ Tender Risk } \\
\hline T 1 & Risk of corruption. & 4 & 4 \\
\hline T 2 & Risk of bad quote for the project (defining the limits of profitability). & 2 & 2 \\
\hline T 3 & Risk of incurring excessive costs (or too low) for marketing and lobbying. & 3 & 3 \\
\hline $\mathrm{T} 4$ & Risk of tender cancellation. & 3 & 4 \\
\hline T 5 & Risk of using predatory pricing by competitors. & 2 & 3 \\
\hline T 6 & Client's reliability risk. & 3 & 4 \\
\hline \multicolumn{4}{|c|}{ Detailed Design Risk } \\
\hline DD 1 & Risk of overestimating the costs of the project. & 3 & 4 \\
\hline DD 2 & Risk of improper design team selection. & 1 & 4 \\
\hline DD3 & Risk of improper technology selection (type of construction, materials). & 2 & 5 \\
\hline DD4 & Risk of decrease of aesthetic level (requires the knowledge of investor preferences). & 3 & 3 \\
\hline \multicolumn{4}{|c|}{ Construction Risk } \\
\hline $\mathrm{C} 1$ & Risk of timely supply of construction materials. & 3 & 4 \\
\hline $\mathrm{C} 2$ & Risk of construction materials quality and maintaining standards. & 3 & 5 \\
\hline C 3 & Risk of equipment failure and bad work schedule & 2 & 3 \\
\hline $\mathrm{C} 4$ & Risk of employees' qualification and performance & 1 & 4 \\
\hline C 5 & Risk of extending the scope of work. & 3 & 3 \\
\hline C 6 & $\begin{array}{l}\text { Risk of poor work organization, management of material resources, supplies and } \\
\text { personnel. }\end{array}$ & 2 & 5 \\
\hline \multicolumn{4}{|c|}{ Financial Risk } \\
\hline F 1 & Risk of political instability. & 3 & 5 \\
\hline F 2 & Risk of economic instability (Inflation and Exchange rate) & 4 & 4 \\
\hline F 3 & Risk of recession in the industry. & 1 & 5 \\
\hline F 4 & Risk of improper cost plan. & 2 & 4 \\
\hline F 5 & Risk of client credibility. & 4 & 4 \\
\hline F 6 & Risk of contract precision (change of objectives during the project, badly defined scope of & 2 & 4 \\
\hline
\end{tabular}




\begin{tabular}{|c|c|c|c|}
\hline CODE & CATEGORIES & $\begin{array}{l}\text { PROBABILITY } 1 \\
\text { (rare)-5 (very frequent) }\end{array}$ & $\begin{array}{l}\text { IMPACT } 1 \text { (very } \\
\text { low)-5 (very high) }\end{array}$ \\
\hline \multicolumn{4}{|c|}{ work and subject for commissioning). } \\
\hline \multicolumn{4}{|c|}{ Project Management Risk } \\
\hline PM 1 & Risk of project team conflicts. & 1 & 3 \\
\hline PM 2 & Risk of scheduling errors and contractor delays. & 3 & 4 \\
\hline PM 3 & Risk of failure to comply with contractual quality requirements. & 3 & 3 \\
\hline \multicolumn{4}{|c|}{ Environmental Risk } \\
\hline En 1 & Risk of Incomplete Environmental Analysis. & 3 & 3 \\
\hline En 2 & New alternatives required to avoid, mitigate or minimize environmental impact & 2 & 3 \\
\hline \multicolumn{4}{|c|}{ External Risk } \\
\hline Ex 1 & Risk of objections from the public. & 3 & 4 \\
\hline Ex 2 & Risk of emerging new stakeholders and change of request. & 2 & 2 \\
\hline Ex 3 & Risk of law compliance and enforcement. & 2 & 3 \\
\hline Ex 4 & Risk from natural forces & 3 & 4 \\
\hline
\end{tabular}

From table 7 and figure 7 above, many risk factors were established to be significant by the respondents under the risks categories. Under the Tender risk category, Risk of corruption was the most frequently mentioned risk factors. Under the Financial risk category, Risk of economic instability (Inflation and Exchange rate) as well as Risk of client credibility was among the most frequently mentioned risk factors.

Respondents revealed that these risk events are usually responsible for the poor delivery and quality of work, accompanied with delays and other associated losses. Risks that are associated with high probability and high impact are required to undergo further analysis, including quantification and thorough risk management.

\subsection{Results of Most Frequently Risk Response Techniques Used in Construction Projects}

In accordance with the survey conducted, the respondents were made to share their opinions on some risk response tools and techniques to ascertain which of them is most frequently use or apply in construction projects management.

The results of this were analyzed and presented in the form of a bar chart. The Figure 8 below illustrates the analyzed results of the most frequently used risk response techniques employed by the respondents.

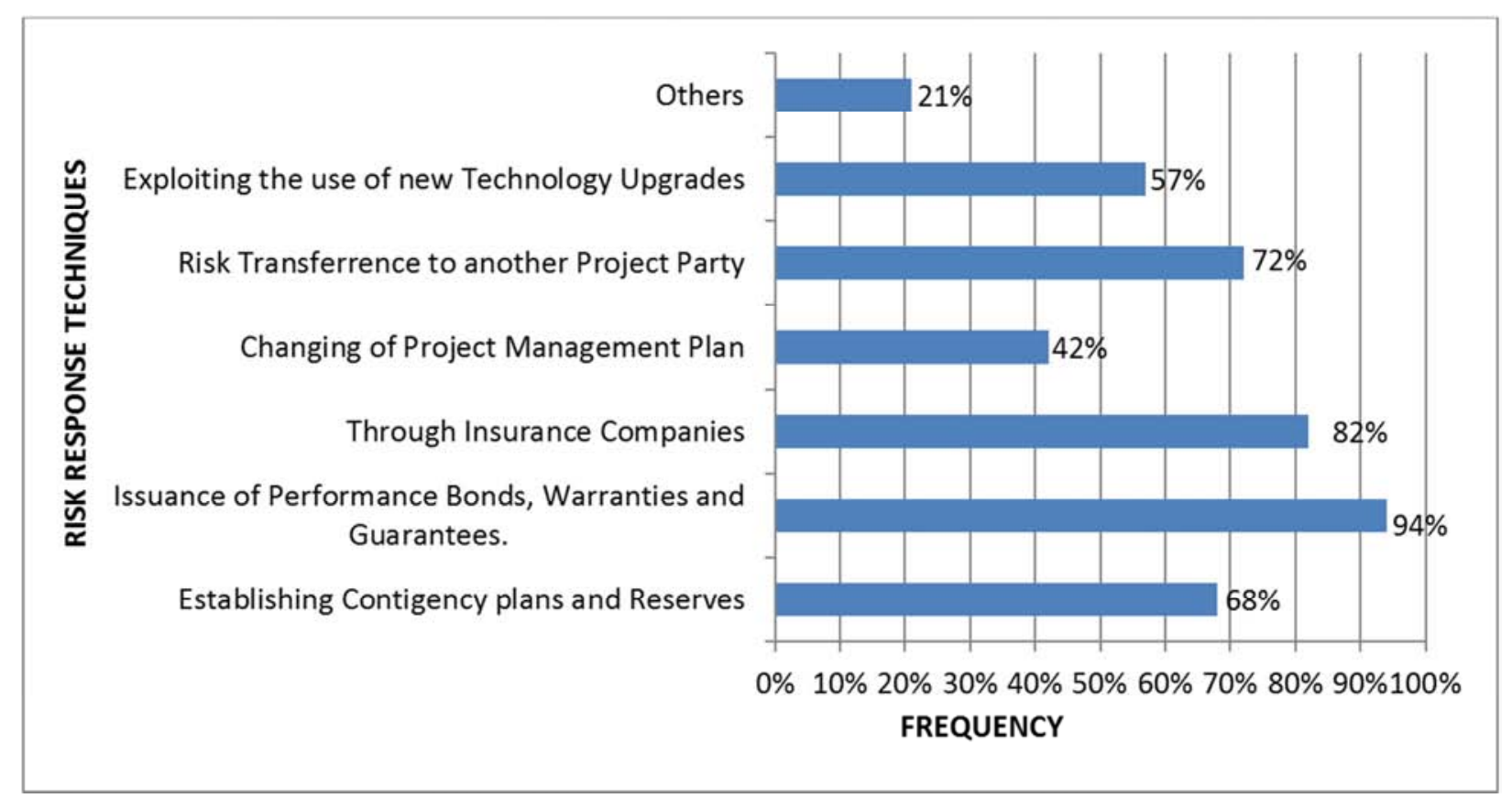

Figure 8. (Most Frequently Used Risk Response Techniques in by the respondents).

From figure 8 above, the most frequently used risk response technique according to the respondents is through the issuance of performance bonds, warranties and guarantees with $94 \%$ of the respondents' in total agreement of such technique. The next frequently used technique is through Insurance Companies which was agreed by $82 \%$ of the respondents. $72 \%$ of the respondents also agreed to the risk response technique of risk transference to another project party. $68 \%$ of the respondents also agreed on the technique of establishing Contingency Plan and Reserves. 57\% of the respondents also agreed on the technique of exploiting the use of new technology upgrades. $42 \%$ of the respondents also agreed on the technique of changing the project management plan and $21 \%$ of the respondents represent other Risk 
Response Techniques.

\subsection{Results of Most Frequently Risk Analysis Practices Used in Construction Projects}

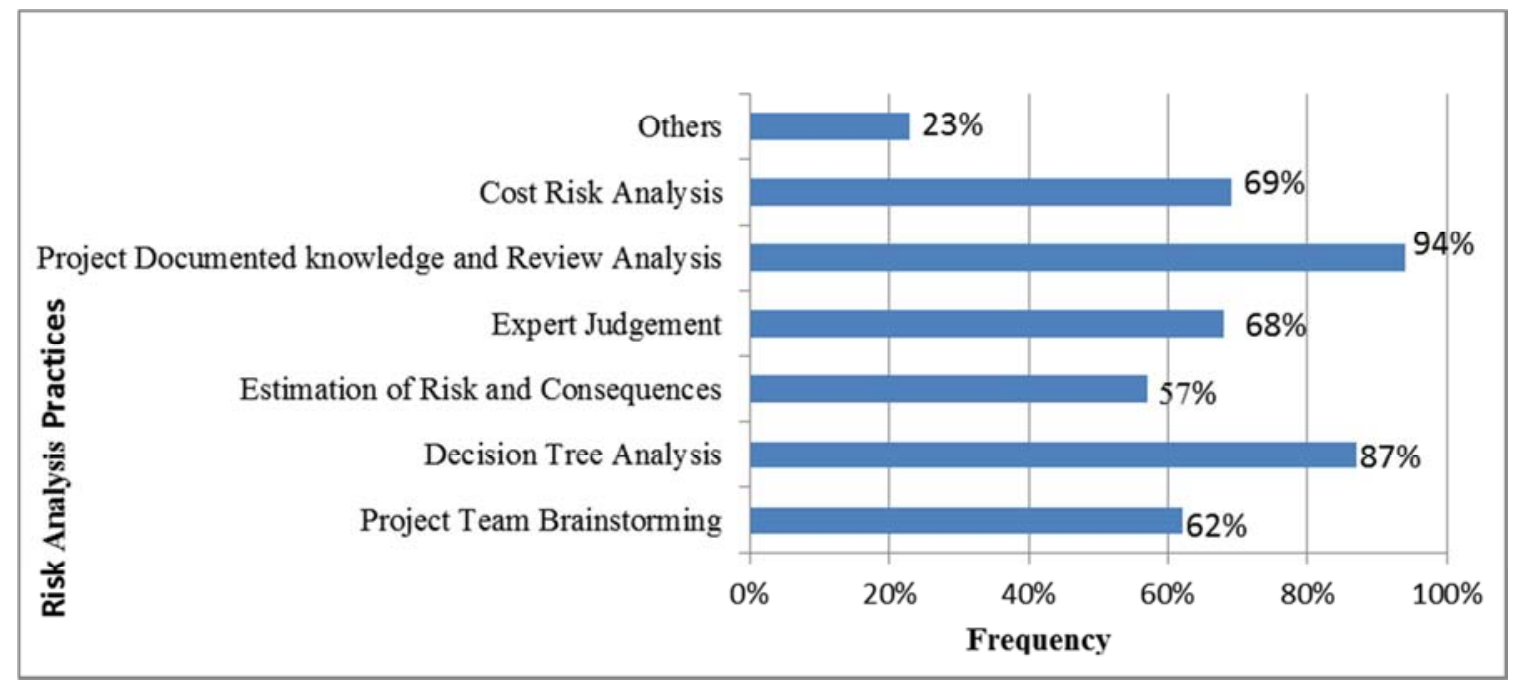

Figure 9. (Most Frequently Used Risk Analysis Practices by the respondents).

Based on the data and information generated form the survey, the respondents shared their opinions on the risk analysis practices which are frequently apply in construction project.

From figure 9 above, the most frequently used risk analysis practice according to the respondents is Project Documented knowledge and Review Analysis which was agreed by $94 \%$ of them. The next frequently practice used is the application of the Decision Tree Analysis which is represented by $87 \%$ of the respondents. $69 \%$ of the respondents also agreed to the practice of the Cost Risk Analysis, $68 \%$ of the respondents also agreed on the practice of Expert Judgment, $62 \%$ of the respondents also agree on the practice of Project Team Brainstorming, 57\% of the respondents agree to the practice of Estimation of Risk and Consequences analysis and $23 \%$ of the respondents represent other Risk Analysis Practices.

\section{Conclusion}

Various studies and scientific research derived from everyday life have shown that risk is a measurable entity and therefore predictable. Modern science also provides us with many tools, techniques and methods to identify and measure risk such as a new and more perfect programs and systems to calculate the scale and magnitude of risk occurrence. It is also realized that a correctly executed project plan, with identified risk which is responded and tackled at the early stage or at the onset may at a later stage create an efficient and a successful project in construction industry.

Qualitative methods of risk assessment or analysis are the most frequently used in construction companies or industry ahead of quantitative methods. So in construction project risk management, risks may be compared by placing them on a matrix of risk impact against a probability. Mitigation options are then derived from predefined limits to ensure the risk tolerance of the construction industry.

In a nut shell, Risk management has become one of the most challenging aspect of managing Construction and software projects. Risk management not only helps in avoiding crisis situations but also aids in remembering and learning from past mistakes. While we can never predict the future with certainty, we can apply a simple and streamlined risk management process to predict the uncertainties in the projects and minimize their occurrence or impact of these uncertainties. This certainly is not the end of the journey for us on the effective risk management in construction projects. It is therefore a constant learning process to be able to constantly improve upon practices in order to adapt and increase the process efficiency of dealing with risk in construction projects as well as its successful execution. This will therefore improves the chance of successful project completion and reduces the consequences of those risks.

\section{References}

[1] Elkington, P., and Smallman, C. (2002). Managing project risks: A case study from the utilities sector. International Journal of Project Management, 20, 49-57.

[2] J. Tamosaitiene, E. Kazimieras, and Z. Turskis, (2013) "Multicriteria risk assessment of a construction project," Vilnius Gediminas Technical University, Department of Construction Technology and Management, Sauletekio Ave. 11, LT-10223, pp. 129-133.

[3] Project Management Institute. (2013) A Guide to the Project Management Body of Knowledge (PMBOK® Guide) - Fifth Edition.

[4] S. K. Kamane and S. A. Mahadik, "Risk management in construction industry," IOSR Journal of Mechanical and Civil Engineering (IOSR-JMCE), pp. 59-65. 
[5] https://theconstructor.org/construction/risk-managementconstruction-projects/24873/.

[6] KarimiAzari, et al. (2011). Risk assessment model selection in construction industry, Expert Systems with Applications, 38, 9105-9111.

[7] Bannerman, P. L. (2008). Risk and risk management in software projects: A reassessment. The Journal of Systems and Software, 81 (12), 2118-2133.

[8] https://fardapaper.ir/mohavaha/uploads/2018/07/FardapaperRisk-management-in-construction-projects.pdf.

[9] Paweł Szymański / Procedia Engineering 208 (2017) 174-182.

[10] Zou PXW, Zhang G, Wang J. Understanding the key risks in construction projects in China. Int J Project Manage 2007; 25 (6): 601-614.
[11] https://www.workamajig.com/blog/project-risk-management.

[12] Wang MT, Chou HY. Risk allocation and risk handling of highway projects in Taiwan. J Manage Eng 2003; 19 (2): 6068 .

[13] A. Dziadosz and M. Rejment, (2015) "Risk analysis in construction project - chosen methods," 15th GermanLithuanian-Polish Colloquium (ORSDCE 2015), pp. 258-265.

[14] Kapliński O.: Risk Management of Construction Works by Means of the Utility Theory: a Case Study. Procedia Engineering. - 2013, 57, 533539.

[15] S. H. A. Kalkhoran, G. Liravi, and F. Rezagholi, (2014) "Risk management in construction projects," International Journal of Engineering Trends and Technology (IJETT), vol. 10, no. 3. 